\title{
Once Daily High-dose Radiation ( $\geq 60$ Gy) Treatment in Limited Stage Small Cell Lung Cancer
}

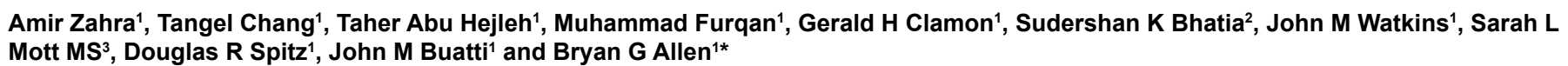

${ }^{1}$ University of lowa Hospitals and Clinics, lowa City, IA, USA

${ }^{2}$ Albany Stratton VA Medical Center, Albany, NY, USA

${ }^{3}$ Holden Comprehensive Cancer Center, University of lowa, lowa City, IA, USA

\begin{abstract}
Objective: To investigate outcomes and prognostic factors in patients treated with once daily high-dose ( $\geq 60 \mathrm{~Gy}$ ) radiation therapy (HDRT) and concurrent platinum-based chemotherapy in limited stage small cell lung cancer (LSSCLC). While we await current phase III trials to determine optimal radiation dose fractionation schemes in LS-SCLC, we report our experience in LS-SCLC with once daily HDRT. We hypothesized that HDRT would achieve similar efficacy and tolerability as twice daily therapy.
\end{abstract}

Methods: We conducted a single institution retrospective review of all patients with LS-SCLC who underwent curative intent treatment from 2005-2013. Patients treated with HDRT ( $\geq 60 \mathrm{~Gy}$ ) and concurrent chemotherapy (cisplatin or carboplatin and etoposide) were included in our analysis. Clinicopathologic variables assessed include gender, performance status, time to treatment, response to treatment, toxicity, volumetric tumor response at 3 months and use of prophylactic cranial irradiation (PCl).

Results: 42 patients with LS-SCLC who initiated concurrent chemoradiation from 2005 to 2013 were included in the analysis. 38 patients $(90 \%)$ completed definitive treatment to the lung; $16(38 \%)$ also completed $\mathrm{PCl}$. Median failure free survival (FFS) and overall survival (OS) were 11.9 and 23.1 months, respectively. Two-year and 5 year OS rates were $47 \%(\mathrm{Cl}=30-62 \%)$ and $21 \%(\mathrm{Cl}=7-38 \%)$, respectively. On univariate analysis, $\mathrm{PCl}$ was associated with improved FFS but this was not significant $(p=0.18)$. Gender was the only co-variate significantly associated with statistical differences in FFS $(p=0.03)$ and OS $(p=0.02)$. Grade 3 and 4 esophagitis were $10.5 \%$ and $2.6 \%$, respectively. Pre-HDRT tumor volume and 3-month post-treatment tumor volume were both associated with FFS $(p<0.01)$ but not OS.

Conclusion: In this single institution series, daily HDRT demonstrated a 2 year OS of $47 \%$ in LS-SCLC. This compares well to the historical survival of daily fractionation (47\%) from INT 0096 reported by Turrisi et al. Male gender was predictive of significantly worse FFS and OS. Once daily HDRT has similar OS to twice-daily radiation schemes; however, further studies assessing once daily HDRT for LS-SCLC are warranted.

Keywords: High-dose radiation therapy; Limited stage small cell lung cancer; Once daily therapy

\section{Introduction}

Small cell lung cancer (SCLC) accounts $3 \%$ of all new cases of lung cancer in the United States [1,2]. Most patients at diagnosis have extensive stage disease; however, in a third of new cases, disease is confined to a hemithorax, mediastinum or supraclavicular lymph nodes, which is categorized as limited stage SCLC (LS-SCLC). Five year survival rate for patient with LS-SCLC is approximately $25 \%[3,4]$.

Meta-analyses of multiple randomized controlled trials in LS-SCLC demonstrated that concurrent radiation with chemotherapy improves patient outcomes significantly [3,5-10]. However, the optimal radiation dose-fractionation regimen is yet to be established.

Multiple thoracic radiation treatment strategies have been investigated in an effort to find the best dose-fractionation scheme. Cancer and Leukemia Group B (CALGB) 8837 determined the maximum tolerated dose (MTD) of $70 \mathrm{~Gy} / 35$ fractions administering radiation daily whereas in twice daily treatment MTD was 45 Gy in 30 fractions [11]. Analysis of CALGB trials (CALGB 30206, 30002 and 39808) utilizing $70 \mathrm{~Gy}$ in 35 daily-fractions demonstrated 2 year survival rate of $37 \%$ [12]. Examining accelerated high-dose radiation therapy (HDRT) via concomitant boost, a phase II study by the Radiation Therapy Oncology Group (RTOG), administered 61.2 Gy in 34 fractions and showed comparable 2 year survival rate of $36.6 \%$ with $18 \%$ grade $\geq 3$ esophagitis [13].
Preclinical and a few pilot clinical studies have demonstrated that the small cell lung cancer dose-response curve lacks a shoulder so a relatively low dose of radiation per fraction can kill malignant cells exponentially, while sparing normal tissues. Based on these findings, Turrisi et al. conducted a phase III intergroup trial (INT 0096), comparing twice daily vs. once daily radiation to $45 \mathrm{~Gy}$ concurrently with cisplatin and etoposide. This study resulted in 2 year survival rate of $47 \%$ in patients who received twice daily radiation, and $10 \%$ improvement in 5 year OS compared to patients who received once daily treatment. Incidence of grade $\geq 3$ esophagitis, infectious and pulmonary complications were $32 \%, 9 \%$ and $6 \%$ respectively [14]. This trial set the standard for managing LS-SCLC; however, patterns of care studies revealed that only $21 \%$ of LS-SCLC patients received twice-daily radiation therapy in 2006-2007 [15,16]. Under-utilization

*Corresponding author: Bryan G. Allen, University of lowa Hospitals and Clinics, 200 Hawkins Drive, 01621 PFPW, lowa City, IA 52242, USA, Tel: 319-356-3693 Fax: 319-356-1530; E-mail: bryan-allen@uiowa.edu

Received June 11, 2016; Accepted July 19, 2016; Published July 26, 2016

Citation: Zahra A, Chang T, Hejleh TA, Furqan M, Clamon GH, et al. (2016) Once Daily High-dose Radiation ( $\geq 60 \mathrm{~Gy}$ ) Treatment in Limited Stage Small Cell Lung Cancer. J Oncol Transl Res 2: 108. doi: 10.4172/2476-2261.1000108

Copyright: ( 2016 Zahra A, et al. This is an open-access article distributed under the terms of the Creative Commons Attribution License, which permits unrestricted use, distribution, and reproduction in any medium, provided the original author and source are credited. 
of this effective regimen is mainly due to practical issues of twice daily regimen and its perceived toxicities $[17,18]$.

Since once daily radiation is widely adopted, CALGB 30610/RTOG 0538 and Concurrent ONce-daily VErsus twice-daily RadioTherapy (CONVERT) studies are looking at direct comparison of various once daily radiation schedules. However, final results of these trials are not anticipated for some time. In an attempt to guide patient's decision making, we performed a retrospective analysis of patients who underwent daily HDRT concurrently with standard chemotherapy at our institution for LS-SCLC and report their outcomes in this manuscript. We hypothesized that daily single-fraction HDRT with concurrent chemotherapy would achieve similar efficacy and tolerability as twice daily radiation therapy.

\section{Methods}

\section{Patient selection}

After institutional review board approval, a retrospective chart review of all patients treated at our institution for LS-SCLC was carried out. Patients were selected if they initiated curative intent therapy with concurrent chemotherapy and HDRT $\geq 60$ Gy from 2005 to 2013.

\section{Treatment and follow-up}

Treatment planning for all patients was carried out using the Pinnacle treatment planning system (Phillips Medical Systems, Fitchburg, WI) and beginning in 2006, 4D-CT-planning software (Siemens Medical Solutions, Concord, CA). Target volume delineation consisted of gross tumor volume (GTV) including clinically or pathologically involved lymph nodes identified by Positron Emission Tomography/Computed Tomography (PET/CT) scans without elective nodal targeting. CTV and ITV were created to encompass the tumor motion at the discretion of the treating radiation oncologist. Planning target volume (PTV) expansion of $0.5 \mathrm{~cm}$ was added to account for daily set up errors. Respiratory gating after $4 \mathrm{D}-\mathrm{CT}$ was utilized when tumor motion was greater than $1 \mathrm{~cm}$.

Treatment was delivered using 6 or $10 \mathrm{MV}$ photons using either $3 \mathrm{D}$ conformal or intensity modulated radiation therapy depending on optimal dose distribution as determined by the attending physician. Chemotherapy regimen including dose and timing were confirmed in treatment records. Patients were seen at least weekly during radiotherapy to determine tolerance to treatment. PCI was administered after appropriate response to definitive therapy and post treatment brain MRI confirmed absence of intracranial disease. On and post-treatment records were reviewed for toxicity, hospitalizations, and disease recurrence. Toxicity was determined retrospectively by reviewing on-treatment assessments, hospital records, laboratory values and the administration of narcotic medications according to the Common Toxicity Criteria for Adverse Events (CTCAE v4).

\section{Tumor response assessment}

The pre-treatment staging CT and the 3 month post-treatment CT were imported into Velocity treatment planning software (Varian; Palo Alto, CA). Pre-treatment tumor and involved lymphadenopathy (GTV) was measured in its largest dimension and the sum of these values recorded. Three-month post-treatment GTV measurements were repeated in the same manner and RECIST (response evaluation criteria in solid tumors) was recorded using previously established methods [19].

The pre-treatment staging CT with PET (88\%) followed by the 3-month post treatment CT scans were utilized to determine tumor volume response. Tumor and involved lymph nodes (GTV) were contoured on each individual CT slice to determine total tumor burden volume in cubic centimeters and response was calculated using the equation:

Tumor Volume Response $=$ pretreatment tumor volume posttreatment tumor volume / pretreatment tumor volume ${ }^{\star} 100 \%$.

\section{End points}

Clinical end points, OS and FFS, were determined through assessment of post-treatment imaging and clinical follow-up. All thoracic failures on imaging were assessed with a pre-treatment CT in order to categorize failure as regional in-field, regional in-and-out of field, regional and distant, or distant only. OS was measured from the date of treatment initiation to the date of death from any cause. FFS was measured from date of treatment initiation to date of recurrence or date of death from any cause. Patients alive or, alive without recurrence were censored at date of last follow-up for OS and FFS, respectively.

\section{Statistical Analysis}

Of the 42 patients identified, 4 patients did not complete primary treatment and were excluded from the analysis. Survival probabilities for OS and FFS were estimated and plotted using the Kaplan-Meier method. Estimates along with $95 \%$ point wise confidence intervals were reported. For comparisons of the survival distributions, the log-rank test was used. Univariable Cox proportional hazards regression models were used to assess the effects of prognostic variables on the outcomes of interest. Prognostic variables included: gender, age at diagnosis, T stage, Eastern Cooperative Oncology Group (ECOG) performance status, receipt of PCI duration of radiation, treatment duration, time between biopsy and treatment completion, and treatment response. All statistical testing was two-sided and assessed for significance at the 5\% levels using SAS v9.4 (SAS Institute; Cary, NC).

\section{Results}

\section{Patient population}

64 patients underwent workup and treatment for LS-SCLC at our institution from 2005 to 2013. Of those, 22 were excluded due to sequential chemoradiation, radiation initiation after 2 cycles of chemotherapy, and planned radiation $<60 \mathrm{~Gy}[3,12] .42$ underwent treatment planning with curative intent consisting of HDRT ( $\geq 60 \mathrm{~Gy}$ ) and concurrent chemotherapy. Staging studies included endobronchial ultrasound or mediastinoscopy for lymph node evaluation in all patients and PET imaging was completed in $88 \%$ of these patients. The staging CT was evaluable in 40 patients. Thirty-eight of the 42 patients completed concurrent HDRT with curative intent and underwent outcomes analysis. Four patients terminated definitive therapy between 5 and 25 fractions and went to hospice care, including one patient who suffered from Lambert-Eaton Myasthenic Syndrome. Two patients were unable to tolerate platinum based chemotherapy due to impaired renal function, one of whom was unable to complete definitive HDRT.

The median age of patients was 63 with $58 \%$ males and ECOG performance status was 2 or less in $97 \%$. The most common radiation regimen prescribed was $61.2 \mathrm{~Gy}$ in 34 fractions ( $82 \%$ of patients). The most common chemotherapy regimen prescribed was carboplatin (AUC 5), etoposide $\left(100 \mathrm{mg} / \mathrm{m}^{2}\right)$, being utilized approximately $3: 1$ compared to cisplatin, etoposide. PCI was administered to 16 patients (38\%). Radiation was initiated at a median of 9.5 days after the first chemotherapy cycle. Reasons for not pursing PCI in 22 patients 
were patient refusal, poor performance status, vascular disease and recurrence with intracranial disease on MRI, and other unknown reasons $[2,3,5,9]$.

\section{Failures-free and overall survival}

The median follow-up was 17.2 months (range: 0.7-102.6 months). Of the 38 patients who completed definitive treatment, $26(68 \%)$ had died. The median OS was 23.1 months. Two year and five year OS rates were $47 \%(30-62 \%)$ and $21 \%(7-38 \%)$, respectively. The median FFS was 11.9 months. Two year and five year FFS rates were 32\% (18-47\%) and $14 \%(4-30 \%)$, respectively. In univariate analysis, female gender was significantly associated with better FFS $(p=0.03)$ and OS $(p=0.02)$.

\section{Recist response}

Post treatment imaging assessment was completed in 34 patients for whom post-treatment imaging was available. Response assessment using RECIST at three months post treatment classified response as complete response in 10 patients $(26.3 \%)$, partial response in 20 patients $(52.6 \%)$, and stable disease (SD) in 4 patients (10.5\%). In patients who completed concurrent HDRT, there were no instances of progressive disease on imaging. Treatment response was not associated with FFS or OS.

\section{Volumetric response}

Imaging was available for three-month post-treatment tumor burden quantification in 34 patients. Tumor response to definitive therapy was measured in cubic centimeters with an average reduction in volume of $91 \%(\mathrm{SD}=10.6)$. Pre-HDRT tumor volume and residual tumor volume at 3 months were both associated with FFS $(\mathrm{p}<0.01)$ but not OS.

\section{Toxicity}

Treatment-related toxicities are summarized in Tables 1 and 2 and Figure 1 . Grade $\geq 3$ esophagitis was seen in $13.1 \%$ of patients. No grade $\geq 3$ pneumonitis was observed but $8 \%$ of patients did develop grade 2 pneumonitis. Twelve patients (31.6\%) required hospitalization for any cause during HDRT. Four of those were admitted for grade 3 febrile neutropenia. Other causes for hospitalization included odynophagia, pneumonia, dehydration, bowel obstruction, and severe weakness. There were no treatment-related deaths associated with concurrent chemoradiation.

\section{Patterns of treatment failure}

Thirty-eight patients completed definitive treatment and could be evaluated for disease recurrence. Four had post-treatment imaging completed at an outside institution and were not available for analysis. Twenty patients (52.6\%) were free of disease at last known follow-up. Most recurrences were 'distant only' ( 9 patients, 23.7\%) and this was most commonly seen in brain (6 patients). The remaining failures were 'regional in-field' (3 patients, 7.9\%), 'regional in-and-out of field' (1 patient, 2.6\%), as well as 'regional and distant' recurrence (5 patients, $13 \%)$. Hence $36.7 \%$ of patients had some component of distant failure.

\section{Discussion}

Selecting an optimum radiation dose-fractionation regimen for the treatment of LS-SCLC remains an unanswered question in the clinical literature. Since the publication of INT 0096, many groups have investigated different radiation dose regimens for LS-SCLC with concurrent chemotherapy [14] (Tables 3 and 4). These studies show a range of 2 year OS from 32-64\% [3,11-14,20-35]. INT 0096 demonstrated $47 \%$ OS at 2 years with twice daily treatment compared to $41 \%$ with once daily regime [14]. Here, we present our experience with once daily HDRT ( $\geq 60$ Gy) and report 2 year OS of $47 \%$ which compares well to previously reported prospective and retrospective studies.

Although many studies have published outcomes in LS-SCLC, few have investigated HDRT with concurrent platinum based chemotherapy in LS-SCLC. Rutter et al. analyzed outcomes of 1228 LSSCLC patients from the National Cancer Database and did not find any statistically significant differences in the median survival of patients according to the radiation dose-regimen received (70 Gy daily, 61.2 Gy daily, 45 Gy twice daily) [29]. They do not describe toxicity data. It is possible that these regimens may not differ from each other in terms of efficacy; however, difference in toxicities and ease of treatment delivery can make one regimen superior to the other.

The CALGB 30610-RTOG 0538 study was designed to evaluate three different radiation regimens in a randomized fashion: $70 \mathrm{~Gy}$ in 35 single daily fractions, 61.2 Gy in 34 fractions ( 16 once daily fractions followed by 18 twice daily fractions as concomitant boost) and $45 \mathrm{~Gy}$ in 30 twice-daily fractions. The hybrid single/twice daily treatment arm consisting of $61.2 \mathrm{~Gy} / 34$ fractions was dropped at interim analysis due to toxicity. A similar effort is ongoing in Europe where the CONVERT study is randomizing good performance status patients to once daily HDRT (66 Gy/33 fractions) versus twice-daily treatment (45 Gy/30 fractions) [36].

\begin{tabular}{|c|c|}
\hline \multicolumn{2}{|c|}{ Characteristics of limited stage small cell lung cancer patients $(\mathrm{N}=38$} \\
\hline Age- $-\mathrm{yr}$ & \\
\hline Median & $63(39-83)$ \\
\hline \multicolumn{2}{|l|}{ Sex } \\
\hline Male & $22(57.9)$ \\
\hline Female & $16(42.1)$ \\
\hline \multicolumn{2}{|l|}{ Race } \\
\hline African American & $2(5.3)$ \\
\hline Caucasian & $36(94.7)$ \\
\hline \multicolumn{2}{|l|}{ ECOG Performance Status } \\
\hline $0-1$ & $29(76.3)$ \\
\hline 2 & $8(21.1)$ \\
\hline$>2$ & $1(2.6)$ \\
\hline \multicolumn{2}{|l|}{ Pre-treatment Weight Loss } \\
\hline$>5 \%$ & $3(7.9)$ \\
\hline \multicolumn{2}{|l|}{ Staging Tumor Stage } \\
\hline T1-2 & $21(55.2)$ \\
\hline T3 / T4 & $8 / 8(21.0 / 21.0)$ \\
\hline \multicolumn{2}{|l|}{ Node Stage } \\
\hline No & $3(7.9)$ \\
\hline N1 & $2(5.3)$ \\
\hline N2 & $26(68.4)$ \\
\hline N3 & $6(15.8)$ \\
\hline \multicolumn{2}{|l|}{ Primary treatment } \\
\hline $60-62 \mathrm{~Gy} / 30-34 \mathrm{fx}$ & $35(92.1)$ \\
\hline $63-66 \mathrm{~Gy} / 33-35 \mathrm{fx}$ & $3(7.9)$ \\
\hline Cisplatin / etoposide & $10(26.3)$ \\
\hline Carboplatin / etoposide & $27(71.1)$ \\
\hline Etoposide alone & $1(2.6)$ \\
\hline
\end{tabular}

Table 1: Patient Characteristics. Complete staging was unavailable for one patient. All patients underwent treatment planning with HDRT $\geq 60 \mathrm{~Gy}$ and concurrent chemotherapy. Thirty-eight patients completed primary therapy with 16 receiving $\mathrm{PCl}$. Chemotherapy agent was unknown in one patient who did not complete primary treatment. 
Citation: Zahra A, Chang T, Hejleh TA, Furqan M, Clamon GH, et al. (2016) Once Daily High-dose Radiation ( $\geq 60$ Gy) Treatment in Limited Stage Small Cell Lung Cancer. J Oncol Transl Res 2: 108. doi: 10.4172/2476-2261.1000108

Page 4 of 7

\begin{tabular}{|c|c|c|c|c|c|c|}
\hline Covariate & Level & $\mathbf{N}$ & FFS & & OS & \\
\hline & & & Hazard Ratio $(95 \% \mathrm{Cl})$ & $p$ value & Hazard Ratio (95\% Cl) & $p$ value \\
\hline Gender & $M: F$ & $21: 17$ & $2.43(1.09-5.44)$ & 0.03 & $2.96(1.20-7.32)$ & 0.02 \\
\hline \multirow[t]{2}{*}{ T stage } & T0-2 & 21 & Ref & - & Ref & - \\
\hline & T3-4 & 16 & $1.21(0.56-2.59)$ & 0.63 & $1.10(0.49-2.50)$ & 0.81 \\
\hline \multirow[t]{2}{*}{ ECOG } & $0-1$ & 29 & Ref & - & Ref & - \\
\hline & $2-4$ & 9 & $1.69(0.73-3.92)$ & 0.22 & $1.73(0.71-4.22)$ & 0.23 \\
\hline \multirow[t]{2}{*}{$\mathrm{PCl}$} & Yes & 16 & $0.60(0.28-1.27)$ & 0.18 & $0.71(0.32-1.59)$ & 0.40 \\
\hline & No & 22 & Ref & - & Ref & - \\
\hline \multirow[t]{3}{*}{ RECIST Response } & PR & 20 & $0.85(0.34-2.11)$ & 0.68 & $0.53(0.2-1.36)$ & 0.18 \\
\hline & SD & 4 & $1.5(0.38-5.86)$ & & $0.77(0.16-3.78)$ & 0.75 \\
\hline & CR & 10 & Ref & - & Ref & - \\
\hline Age at Diagnosis & Units=1 & 38 & $1.0(0.97-1.04)$ & 0.97 & $1.02(0.99-1.06)$ & 0.20 \\
\hline Duration of Radiation (days) & Units $=1$ & 38 & $1.01(0.93-1.10)$ & 0.79 & $1.02(0.94-1.11)$ & 0.65 \\
\hline Chemotherapy Start to End of Radiation days) & Units=1 & 38 & $1.0(0.97-1.04)$ & 0.83 & $1.00(0.96-1.04)$ & 0.83 \\
\hline Biopsy to End of Radiation (days) & Units $=1$ & 38 & $0.99(0.97-1.02)$ & 0.60 & $0.99(0.96-1.02)$ & 0.47 \\
\hline Pre-HDRT Tumor Volume $\left(\mathrm{cm}^{3}\right)$ & Units $=1$ & 35 & $1.01(1.00-1.01)$ & $<.01$ & $1.00(1.00-1.01)$ & 0.55 \\
\hline Post-treatment Tumor Volume $\left(\mathrm{cm}^{3}\right)$ & Units $=1$ & 34 & $1.04(1.02-1.07)$ & $<.01$ & $1.01(0.99-1.03)$ & 0.40 \\
\hline Relative Reduction Tumor Volume $\left(\mathrm{cm}^{3}\right)$ & Units $=1$ & 34 & $1.0(0.96-1.03)$ & 0.80 & $1.01(0.97-1.05)$ & 0.66 \\
\hline
\end{tabular}

Table 2: Univariate analyses according to FFS and OS.
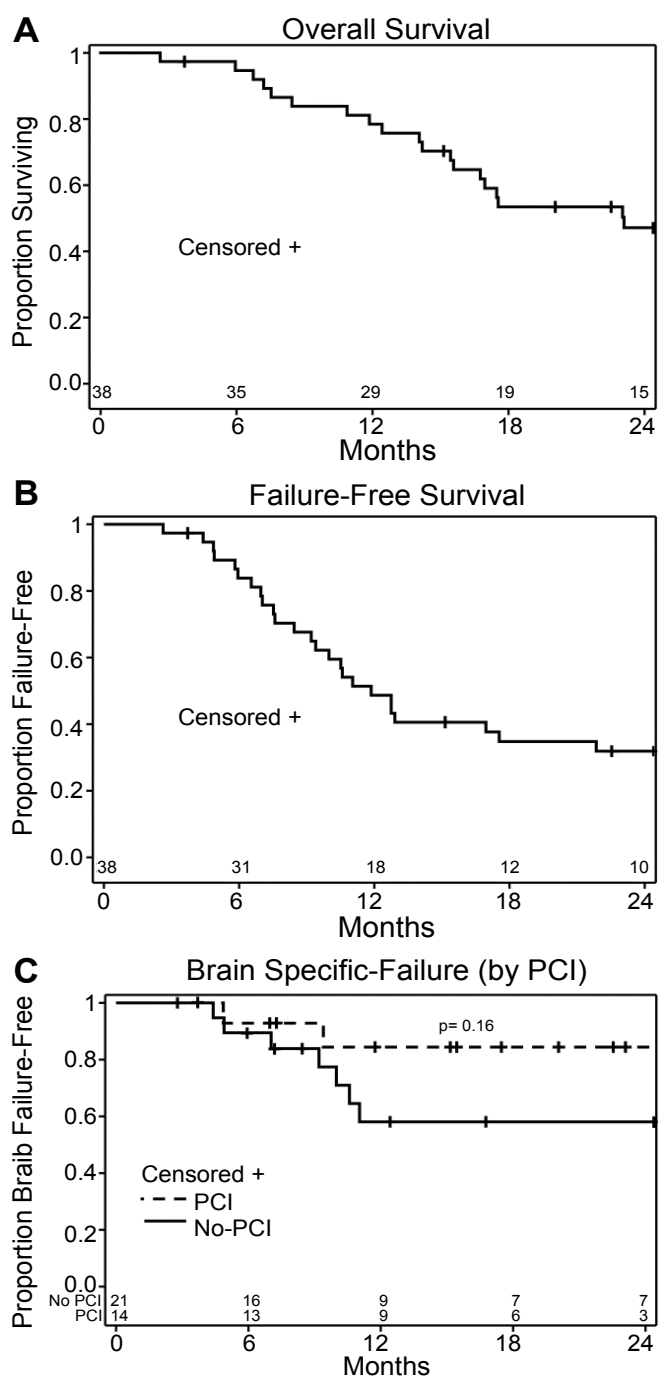

Figure 1: Once daily HDRT has similar treatment efficacy as twice daily radiation therapy. Kaplan-Meier curves for overall survival, failure-free survival and brain specific failure in LS-SCLC patients who complete therapy. Median overall survival was 23.1 months with estimated survival of $47 \%$ at 2 years ( $30-63 \%$ ). Median failure free survival (FFS) in 32 patients who completed definitive therapy was 11.9 months. 2 years FFS was 32\% (18-47\%). Patients alive without disease recurrence were censored at date of last follow-up. 
Citation: Zahra A, Chang T, Hejleh TA, Furqan M, Clamon GH, et al. (2016) Once Daily High-dose Radiation ( $\geq 60$ Gy) Treatment in Limited Stage Small Cell Lung Cancer. J Oncol Transl Res 2: 108. doi: 10.4172/2476-2261.1000108

Page 5 of 7

\begin{tabular}{|c|c|c|c|}
\hline Toxicity & Grade 2 & Grade 3 \\
\hline N=38 & & $4(10.5)$ \\
\hline Esophagitis & $23(60.5)$ & $2(5.3)$ \\
\hline Anemia & $8(21.1)$ & 0 & $1(2.6)$ \\
\hline Thrombocytopenia & $4(10.5)$ & 0 \\
\hline Neutropenia & $5(13.2)$ & 0 & $2(15.8)$ \\
\hline Vomiting & 0 & 0 & 0 \\
\hline Weight loss & $4(10.5)$ & $4(10.3)$ \\
\hline Neutropenic fever & 0 & 0 \\
\hline Pneumonitis & $3(7.9)$ & 0 \\
\hline
\end{tabular}

Hospital admission for any cause for those completing treatment was recorded as $12(31.6 \%)$.

Hematologic lab values were unavailable for 5 subjects. No grade 5 toxicities occurred.

Table 3: Patient toxicities while receiving HDRT.

\begin{tabular}{|c|c|c|c|c|c|}
\hline Study & Outline & Patients & Median Survival (mos.) & Overall Survival & Toxicity \\
\hline \multicolumn{6}{|l|}{ Prospective } \\
\hline Turrisi (1999) & $\left(^{*}\right) 45 \mathrm{~Gy} / 25 \mathrm{fx} \mathrm{QD}$ & 417 & & & Grade 3 esophagitis $11 \%$ \\
\hline \multirow[t]{3}{*}{ Int 0096 Phase 314} & & $(1989-1992)$ & & & Grade 4 esophagitis $5 \%$ \\
\hline & 45 Gy /30fx BID & & 23 & $2 y r$ OS $47 \%$ & Grade 3 esophagitis 27\% \\
\hline & & & & & Grade 4 esophagitis $5 \%$ \\
\hline Salama (2013) & $\left({ }^{* \star}\right) 70 \mathrm{~Gy} / 35 \mathrm{fx}$ & 200 & 19.9 & $2 y r$ OS $37 \%$ & Grade $\geq 3$ esophagitis $23 \%$ \\
\hline CALGB 30904 & & (1999-2005) & & $5 y r$ OS $20 \%$ & Grade 3 pneumonitis $5 \%$ \\
\hline pooled analysis 12 & & & & & Grade 4 pneumonitis $2 \%$ \\
\hline Komaki (2012) & $\left(^{*}\right) 61.2 \mathrm{~Gy} / 34 \mathrm{fx}$ & 71 & 19 & $2 y r$ OS $36.6 \%$ & Grade $\geq 3$ esophagitis $18.4 \%$ \\
\hline RTOG 0239 & & (2003-2006) & & & Grade 3 pneumonitis $9.8 \%$ \\
\hline \multirow[t]{2}{*}{ Phase 213} & & & & & Grade 4 pneumonitis $1.4 \%$ \\
\hline & & & & & Grade 5 pneumonitis $1.4 \%$ \\
\hline Xia (2014) & 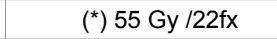 & 59 & 28.5 & $2 \mathrm{yr}$ OS $58.2 \%$ & Grade 3 esophagitis $25 \%$ \\
\hline Shanghai:Phase234 & & $(2007-2012)$ & & & \\
\hline \multicolumn{6}{|l|}{ Retrospective } \\
\hline Rutter (2015) & (NR) 45Gy/30fx BID & 707 & 21.5 & Not reported & Not reported \\
\hline Yale29: National & $61.2 \mathrm{~Gy} / 34 \mathrm{fx}$ & 468 & 20.2 & & \\
\hline \multirow[t]{2}{*}{ Cancer Database } & $70 \mathrm{~Gy} / 35 \mathrm{fx}$ & 53 & & & \\
\hline & & $(1998-2006)$ & & & \\
\hline Nair (2012) & (NR) 50 Gy median & 296 & 21.2 & $2 \mathrm{yr}$ OS $45 \%$ & Not reported \\
\hline Ottawa, Can25 & & $(1996-2001)$ & & & \\
\hline Turaka (2013) & $\left(^{*}\right) 52.2 \mathrm{QD}$ & 215 & 19 & $3 y r$ OS $25 \%$ & Not reported \\
\hline Fox Chase32 & 45 Gy /30fx BID & $(1991-2012)$ & & $5 y r$ OS $16 \%$ & \\
\hline Kim (2014) & 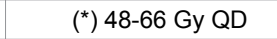 & 125 & 30.6 & $3 y r$ OS $39.1 \%$ & Not reported \\
\hline \multirow[t]{2}{*}{ Seoul, Korea26 } & 45 Gy /30fx BID & 122 & 30.6 & $3 y r$ OS $37.5 \%$ & \\
\hline & & $(2001-2011)$ & & & \\
\hline Tomita (2010) & $\left({ }^{* * *}\right) 45 G y$ BID (37) & 127 & 30 & $3 y r$ OS $44.1 \%$ & Grade 5 pneumonitis $4 \%$ \\
\hline \multirow[t]{3}{*}{ Nagoya, Jap31 } & $<54$ Gy QD (29) & & 14 & 3yr OS $13.8 \%$ & Grade 5 pneumonitis $2 \%$ \\
\hline & $\geq 54 G y$ QD (61) & & 41 & $3 y r$ OS $53.1 \%$ & No esophagitis reported \\
\hline & & $(1997-2007)$ & & & \\
\hline Han (2015) & $\left(^{*}\right) 60 \mathrm{~Gy} / 30 \mathrm{fx}$ & & & & Grade $\geq 2$ pneumonitis $56 \%$ \\
\hline \multirow[t]{4}{*}{ Shandong, China23 } & & 80 & 30.4 & $2 y r$ OS $43.3 \%$ & \\
\hline & vs & & & & Grade $\geq 3$ esophagitis $6 \%$ \\
\hline & 45Gy /30fx BID & 63 & 29.5 & $2 y r$ OS $48.8 \%$ & Grade $\geq 2$ pneumonitis $20 \%$ \\
\hline & & $(2008-2013)$ & & & Grade $\geq 3$ esophagitis $19 \%$ \\
\hline Watkins (2010) & $\left({ }^{* *}\right) \geq 59.4 \mathrm{~Gy}(59.4-$ & 71 & 22.1 & $2 \mathrm{yr}$ OS $43 \%$ & Grade 3 esophagitis $24 \%$ \\
\hline MU South & 70Gy) QD & $(1994-2007)$ & & & Grade 3 pneumonitis 6\% \\
\hline \multirow[t]{2}{*}{ Carolina33 } & $\geq 45 \mathrm{~Gy}$ & & 21.4 & $2 y r$ OS $49 \%$ & Grade 3 esophagitis $20 \%$ \\
\hline & (45-51Gy) BID & & & & Grade 3 pneumonitis $2 \%$ \\
\hline Roof (2003) & (*) $^{*} \geq 50 \mathrm{~Gy}$ & 54 & 29 & $2 \mathrm{yr}$ OS $64 \%$ & Grade $\geq 3$ pneumonitis $31 \%$ \\
\hline \multirow[t]{2}{*}{ Harvard28 } & & $(1987-2000)$ & & $5 y r$ OS $47 \%$ & ( $2 \%$ acute, $31 \%$ fibrosis) \\
\hline & & & & & Grade $\geq 3$ esophagitis $11 \%$ \\
\hline Bettington (2013) & 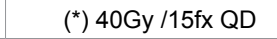 & 38 & 21 & $5 y r$ OS $20 \%$ & Not reported \\
\hline
\end{tabular}


Citation: Zahra A, Chang T, Hejleh TA, Furqan M, Clamon GH, et al. (2016) Once Daily High-dose Radiation ( $\geq 60$ Gy) Treatment in Limited Stage Small Cell Lung Cancer. J Oncol Transl Res 2: 108. doi: 10.4172/2476-2261.1000108

Page 6 of 7

\begin{tabular}{|c|c|c|c|c|c|}
\hline Queensland, Aus20 & 45Gy /30fx BID & 41 & 26 & $5 y r$ OS $25 \%$ & \\
\hline & & $(2000-2009)$ & & & \\
\hline Miller (2003) & $\left(^{* * *}\right) 60 \mathrm{~Gy}$ & 32 & 11.9 & $3 y r$ OS 23\% & Not reported according to \\
\hline \multirow[t]{2}{*}{ Duke27 } & & $(1991-1999)$ & & & concurrent vs sequential \\
\hline & $\left(^{\star}\right) 61.2 \mathrm{~Gy}$ median & 20 & 22.8 & $5 y r$ OS 30\% & $\begin{array}{c}\text { Grade } \geq 2 \text { pneumonitis } 13 \% \text {. One } \\
\text { Grade } 5 \text { pneumonitis. }\end{array}$ \\
\hline \multirow{3}{*}{ Gazula (2013) Harvard22 } & vs & & & & Grade $\geq 2$ esophagitis $24 \%$ \\
\hline & 45Gy /30fx BID & 26 & 22.8 & $5 y r$ OS $30 \%$ & Grade $\geq 2$ pneumonitis $4 \%$ \\
\hline & & $(2005-2010)$ & & & Grade $\geq 2$ esophagitis $44 \%$ \\
\hline \multirow[t]{3}{*}{ Current study } & $(* *) \geq 60$ Gy & 38 & 23.1 & $2 \mathrm{yr} O S 47 \%$ & Grade 3 esophagitis $10.5 \%$ \\
\hline & & (2005-2015) & & & Grade 4 esophagitis 8\% \\
\hline & & & & & Grade 2 pneumonitis $8 \%$ \\
\hline
\end{tabular}

Selected studies investigating dose fractionation in LS-SCLC treated with concurrent chemotherapy and radiation. Most common concurrent chemotherapy regimen specified $\left({ }^{*}\right)$ cisplatin/etoposide, $\left({ }^{* *}\right)$ carboplatin/etoposide, $\left(^{* * *}\right)$ platinum based, (NR) not reported.

Table 4: Summary of previously published LS-SCLC studies.

A platinum-based chemotherapy combined with etoposide and radiation is the standard treatment for LS-SCLC; however, the benefit of using cisplatin versus carboplatin is unresolved. A meta-analysis showed similar survival outcomes for cisplatin versus carboplatinbased regimens in small cell lung cancer [37]. A phase III trial compared cisplatin to carboplatin in SCLC and showed no significant difference in response rate or survival between the two chemotherapies, and the carboplatin regimen was associated with a better toxicity profile [38]. In regards to esophagitis, studies in NSCLC have shown that cisplatin is more likely to be associated with esophagitis than carboplatin [39]. The CALGB 30610/RTOG 0538 study is allowing either cisplatin or carboplatin based chemotherapy with radiation whereas the CONVERT study is restricted to cisplatin. These studies will likely shed more light on the optimal chemotherapy regimen to be used and the incidence of radiation esophagitis in the cases of cisplatin and carboplatin.

Results of ongoing studies will not be available for some time; however, knowledge of patient outcomes who underwent HDRT remains important in guiding treatment selection for LS-SCLC patients. Our single institution retrospective review of HDRT ( $\geq 60 \mathrm{~Gy}$ ) with concurrent platinum based chemotherapy demonstrated comparable efficacy (2year OS $47 \%$, median overall survival of 23.1 months) with the best-reported twice daily regimen [14]. Toxicity profile revealed grade $\geq 3$ esophagitis rate was $13.1 \%$, grade 2 pneumonitis rate was $8 \%$ and no grade $\geq 3$ pneumonitis was seen. In addition, our volumetric tumor assessment showed that pre-HDRT tumor volume was associated with worse FFS $(p<0.01)$ as has been reported by Reymen et al. This may be a useful metric to be utilized in future studies of LS-SCLC for patient's stratification $[40,41]$.

The limitations of our study include those inherent to the retrospective analysis which may include incomplete patient information or imaging as described. In addition, limitations in toxicity assessment from the available treatment information and follow up records is noted.

\section{Conclusion}

Daily HDRT treatment ( $\geq 60$ Gy) with concurrent platinum based chemotherapy in LS-SCLC compares well in efficacy to twicedaily regimen with a better toxicity profile. Prospective studies assessing once-daily HDRT in LS-SCLC and the optimal concomitant chemotherapy regimen are yet to be reported.

\section{Acknowledgements}

This study was supported in part by the Holden Comprehensive Cancer Center CCSG P30-CA08686, Carver Research Program of Excellence in Redox
Biology, and the American Society of Therapeutic Radiation Oncology (ASTRO) grant JF2014-1 (BGA). We appreciate the assistance of Gareth Smith in editing the manuscript and providing his input.

\section{References}

1. American Cancer Society (2016) Cancer Facts and Figures 2016 Atlanta Georgia: American Cancer Society.

2. Zikos E, Ghislain I, Coens C, Ediebah DE, Sloan E, et al. (2014) Health-related quality of life in small-cell lung cancer: A systematic review on reporting of methods and clinical issues in randomised controlled trials. Lancet Oncol 15: e78-89.

3. Amini A, Byers LA, Welsh JW, Komaki RU (2014) Progress in the management of limited-stage small cell lung cancer. Cancer 120: 790-798.

4. Micke P, Faldum A, Metz T, Beeh KM, Bittinger F, et al. (2002) Staging small cell lung cancer: Veterans Administration Lung Study Group versus International Association for the Study of Lung Cancer--what limits limited disease? Lung Cancer 37: 271-276.

5. De Ruysscher D, Pijls-Johannesma M, Bentzen SM, Minken A, Wanders R, et al. (2006) Time between the first day of chemotherapy and the last day of chest radiation is the most important predictor of survival in limited-disease small-cell lung cancer. J Clin Oncol 24:1057-1063.

6. Murray N, Coy P, Pater JL, Hodson I, Arnold A, et al. (1993) Importance of timing for thoracic irradiation in the combined modality treatment of limitedstage small-cell lung cancer. The National Cancer Institute of Canada Clinical Trials Group. J Clin Oncol 11: 336-344.

7. Pignon JP, Arriagada R (1992) Role of thoracic radiotherapy in limited-stage small-cell lung cancer: quantitative review based on the literature versus metaanalysis based on individual data. J Clin Oncol 10:1819-20.

8. Pijls-Johannesma M, De Ruysscher D, Vansteenkiste J, Kester A, Rutten I, et al. (2007) Timing of chest radiotherapy in patients with limited stage small cell lung cancer: a systematic review and meta-analysis of randomised controlled trials. Cancer Treat Rev 33: 461-473.

9. Takada M, Fukuoka M, Kawahara M, Sugiura T, Yokoyama A, et al. (2002) Phase III study of concurrent versus sequential thoracic radiotherapy in combination with cisplatin and etoposide for limited-stage small-cell lung cancer: results of the Japan Clinical Oncology Group Study 9104. J Clin Oncol 20: $3054-3060$

10. Warde P, Payne D (1992) Does thoracic irradiation improve survival and loca control in limited-stage small-cell carcinoma of the lung? A meta-analysis. Clin Oncol 10: 890-895.

11. Choi NC, Herndon JE 2nd, Rosenman J, Carey RW, Chung CT, et al. (1998) Phase I study to determine the maximum-tolerated dose of radiation in standard daily and hyperfractionated-accelerated twice-daily radiation schedules with concurrent chemotherapy for limited-stage small-cell lung cancer. J Clin Oncol 16: 3528-3536.

12. Salama JK, Hodgson L, Pang H, Urbanic JJ, Blackstock AW, et al. (2013) A pooled analysis of limited-stage small-cell lung cancer patients treated with induction chemotherapy followed by concurrent platinum-based chemotherapy and 70 Gy daily radiotherapy: CALGB 30904. J Thorac Oncol 8: 1043-1049. 
Citation: Zahra A, Chang T, Hejleh TA, Furqan M, Clamon GH, et al. (2016) Once Daily High-dose Radiation ( $\geq 60$ Gy) Treatment in Limited Stage Small Cell Lung Cancer. J Oncol Transl Res 2: 108. doi: 10.4172/2476-2261.1000108

13. Komaki R, Paulus R, Ettinger DS, Videtic GM, Bradley JD et al. (2012) Phase II study of accelerated high-dose radiotherapy with concurrent chemotherapy for patients with limited small-cell lung cancer: Radiation Therapy Oncology Group protocol 0239. Int J Radiat Oncol Biol Phys 83: e531-536.

14. Turrisi AT 3rd, Kim K, Blum R, Sause WT, Livingston RB, et al. (1999) Twicedaily compared with once-daily thoracic radiotherapy in limited small-cell lung cancer treated concurrently with cisplatin and etoposide. N Engl J Med 340: 265-271.

15. Movsas B, Moughan J, Komaki R, Choy H, Byhardt R, et al. (2003) Radiotherapy patterns of care study in lung carcinoma. $\mathrm{J}$ Clin Oncol 21: 4553-4559.

16. Komaki R, Khalid N, Langer CJ, Kong FM, Owen JB, et al. (2013) Penetration of recommended procedures for lung cancer staging and management in the United States over 10 years: a quality research in radiation oncology survey. Int J Radiat Oncol Biol Phys 85:1082-1089.

17. Watkins JM, Wahlquist AE, Shirai K, Garrett-Mayer E, Aguero EG, et al. (2009) Factors associated with severe acute esophagitis from hyperfractionated radiotherapy with concurrent chemotherapy for limited-stage small-cell lung cancer. Int J Radiat Oncol Biol Phys 74:1108-1113.

18. Werner-Wasik M, Pequignot E, Leeper D, Hauck W, Curran W (2000) Predictors of severe esophagitis include use of concurrent chemotherapy, but not the length of irradiated esophagus: a multivariate analysis of patients with lung cancer treated with nonoperative therapy. Int J Radiat Oncol Biol Phys 48: $689-696$

19. Eisenhauer EA, Therasse P, Bogaerts J, Schwartz LH, Sargent D, et al. (2009) New response evaluation criteria in solid tumours: revised RECIST guideline (version 1.1). Eur J Cancer 45: 228-247.

20. Bettington CS, Tripcony L, Bryant G, Hickey B, Pratt G, et al. (2013) A retrospective analysis of survival outcomes for two different radiotherapy fractionation schedules given in the same overall time for limited stage small cell lung cancer. J Med Imaging Radiat Oncol 57:105-112.

21. Komaki R, Swann RS, Ettinger DS, Glisson BS, Sandler AB, et al. (2005) Phase I study of thoracic radiation dose escalation with concurrent chemotherapy for patients with limited small-cell lung cancer: Report of Radiation Therapy Oncology Group (RTOG) protocol 97-12. Int J Radiat Oncol Biol Phys 62: 342350.

22. Gazula A, Baldini EH, Chen A, Kozono D (2014) Comparison of once and twice daily radiotherapy for limited stage small-cell lung cancer. Lung 192:151-158.

23. Han D, Hao S, Tao C, Zhao Q, Wei Y, et al. (2015) Comparison of once daily radiotherapy to $60 \mathrm{~Gy}$ and twice daily radiotherapy to $45 \mathrm{~Gy}$ for limited stage small-cell lung cancer. Thorac Cancer 6: 643-648.

24. Jackson MW, Rusthoven CG, Amini A, Gaspar LE, Kavanagh BD (2015) Equivalent Outcomes With Hypofractionated, Accelerated Thoracic Radiation Therapy for Limited-Stage Small Cell Lung Cancer: Does This Represent a Reasonable Strategy in Patients Unable to Attend Twice Daily Treatment? Int J Radiat Oncol Biol Phys 93: E438.

25. Nair J, Sirisegaram A, Nicholas G, Mallick R, Laurie S,et al. (2012) Higher Dose Thoracic Radiation Therapy Is Associated With Improved Overall Survival in Limited-stage Small Cell Lung Cancer: Analysis of the 15-year Experience From a Retrospective Cohort of 296 Patients. Int J Radiat Oncol Biol Phys 84: S577.

26. Kim K, Moon S, Kim Y, Kim T, Cho K, et al. (2014) Treatment Outcomes of Limited-Stage Small Cell Lung Cancer Patients Treated With Concurrent Chemoradiation Therapy: A Comparative Analysis of Different Radiation Dose Fractionation Schedules in a Single Institution. Int J Radiat Oncol Biol Phys 90: S632.

27. Miller KL, Marks LB, Sibley GS, Clough RW, Garst JL, et al. (2003) Routine use of approximately $60 \mathrm{~Gy}$ once-daily thoracic irradiation for patients with limitedstage small-cell lung cancer. Int J Radiat Oncol Biol Phys 56: 355-359.

28. Roof KS, Fidias P, Lynch TJ, Ancukiewicz M, Choi NC (2003) Radiation dose escalation in limited-stage small-cell lung cancer. Int J Radiat Oncol Biol Phys 57: 701-708
29. Rutter CE, Park HS, Corso CD, Yeboa DN, Mancini BR, et al. (2015) Comparison of survival outcomes among standard radiotherapy regimens in limited-stage small cell lung cancer patients receiving concurrent chemoradiation. Lung Cancer 90: 243-248.

30. Takeuchi Y, Matsuura K, Katsuta T, Okabe T, Kagemoto M (2014) 45 Gy Versus 54 Gy of Accelerated Hyperfractionated Radiation Therapy for Patients With Limited-Stage Small Cell Lung Cancer: A Retrospective Analysis of a 7-Year Experience. Int J Radiat Oncol Biol Phys 90: S625.

31. Tomita N, Kodaira T, Hida T, Tachibana H, Nakamura T, Nakahara R, et al. The impact of radiation dose and fractionation on outcomes for limited-stage smallcell lung cancer. Int J Radiat Oncol Biol Phys 76: 1121-1126.

32. Turaka A, Li T, Naik MJ, Unger M, King E, et al. (2013) Twice Daily Versus Once Daily Radiation Therapy in Unselected Limited-Stage Small Cell Lung Cancer Patients: Medicine-Based Evidence. Int J Radiat Oncol Biol Phys 87: S507-S508.

33. Watkins JM, Fortney JA, Wahlquist AE, Shirai K, Garrett-Mayer E, et al. ( 2010) Once-daily radiotherapy to $>$ or $=59.4$ Gy versus twice-daily radiotherapy to $>$ or $=45.0 \mathrm{~Gy}$ with concurrent chemotherapy for limited-stage small-cell lung cancer: a comparative analysis of toxicities and outcomes. Jpn J Radiol 28: 340-348.

34. Xia B, Hong LZ, Cai XW, Zhu ZF, Liu Q, et al. (2015) Phase 2 study of accelerated hypofractionated thoracic radiation therapy and concurren chemotherapy in patients with limited-stage small-cell lung cancer. Int J Radiat Oncol Biol Phys 91: 517-523.

35. Yee D, Hanson J, Butts C, Reiman A, Joy A, et al. (2010) Phase I dose escalation trial of hypofractionated limited-field external beam thoracic radiotherapy for limited-stage small cell carcinoma of the lung. Radiother Oncol 96: 78-83.

36. Faivre-Finn C, Falk S, Ashcroft L, Bewley M, Lorigan P, et al. (2016) Protocol for the CONVERT trial-Concurrent ONce-daily VErsus twice-daily RadioTherapy: an international 2-arm randomised controlled trial of concurrent chemoradiotherapy comparing twice-daily and once-daily radiotherapy schedules in patients with limited stage small cell lung cancer (LS-SCLC) and good performance status. BMJ Open 6: e009849.

37. Rossi A, Di Maio M, Chiodini P, Rudd RM, Okamoto H, et al. (2012) Carboplatinor cisplatin-based chemotherapy in first-line treatment of small-cell lung cancer the COCIS meta-analysis of individual patient data. J Clin Oncol 30:1692-1698.

38. Skarlos DV, Samantas E, Kosmidis P, Fountzilas G, Angelidou M, et al. (1994) Randomized comparison of etoposide-cisplatin vs. etoposide-carboplatin and irradiation in small-cell lung cancer. A Hellenic Co-operative Oncology Group study. Ann Oncol 5: 601-607.

39. Ozcelik M, Korkmaz T, Odabas H, Gemici C, Ercelep O, et al. (2016) Comparison of efficacy and safety of three different chemotherapy regimens delivered with concomitant radiotherapy in inoperable stage III non-small cell lung cancer patients. Tumour Biol.

40. Reymen B, Van Loon J, van Baardwijk A, Wanders R, Borger J, et al. (2013) Total gross tumor volume is an independent prognostic factor in patients treated with selective nodal irradiation for stage I to III small cell lung cancer. Int J Radiat Oncol Biol Phys 85: 1319-1324.

41. Videtic GM (2014) Oncology scan--defining dose, fractionation, and target volume in small cell lung cancer. Int J Radiat Oncol Biol Phys 88: 981-983. 